\title{
Electrokinetic Study of Bovine Serum Albumin Adsorption on Previously Formed PAH/PSS Multilayer ${ }^{\dagger}$
}

\author{
Irena Đapića and Davor Kovačević ${ }^{\mathrm{b}, *}$ \\ ${ }^{a}$ Department of Chemistry and Biochemistry, Faculty of Food Technology and Biotechnology, \\ University of Zagreb, Pierottijeva 6, 10000 Zagreb, Croatia \\ ${ }^{\mathrm{b}}$ Laboratory of Physical Chemistry, Department of Chemistry, Faculty of Science, \\ University of Zagreb, Horvatovac 102a, 10000 Zagreb, Croatia
}

RECEIVED JANUARY 10, 2011; REVISED MARCH 21, 2011; ACCEPTED MARCH 21, 2011

\begin{abstract}
Layer-by-layer structures (e.g. polyelectrolyte multilayers and protein-polyelectrolyte multilayers) play a very important role in surface modification processes. In the present study, electrokinetic measurements were applied for the investigation of poly(allylamine hydrochloride)/poly(sodium 4-styrenesulphonate) (PAH/PSS) multilayer formation, with PAH being a terminal layer, as a function of $\mathrm{pH}$. Additionally, the effect of supporting electrolyte $(\mathrm{KCl})$ concentration on multilayer formation was tested. Silica particles were used as the solid substrate. Furthermore, the adsorption of bovine serum albumin (BSA) on previously formed multilayer was examined as a function of $\mathrm{pH}$ and BSA concentration. It was confirmed that the electrokinetic measurements are suitable for monitoring the formation of various multilayers. In all investigated systems the process of multilayer formation was found to depend on conditions (ionic strength and $\mathrm{pH}$ ) under which the multilayer was formed. Moreover, in the case of BSA, the adsorption on previously formed multilayer BSA concentration also plays a significant role. (doi: $10.5562 /$ cca1822)
\end{abstract}

Keywords: polyelectrolyte multilayers, electrokinetics, adsorption, bovine serum albumin, ionic strength

\section{INTRODUCTION}

Polyelectrolyte multilayers formed on metal oxide surfaces by an alternate adsorption of positively and negatively charged polyelectrolytes, introduced in the early 1990 's by Decher ${ }^{1}$ are promising coatings onto which biological molecules (e.g. proteins) could be adsorbed. In the literature, ${ }^{2-4}$ various examples of investigation of the adsorption of different proteins on previously formed multilayers could be found. Müller and cowork$\mathrm{ers}^{2}$ examined the adsorption of human serum albumin (HSA) on poly(ethyleneimine)/poly(acrylic acid) multilayers using ATR FTIR spectroscopy, while Gergelly et $a l^{3}$ analysed the adsorption of the same protein on poly(L-lysine)/poly(glutamic acid) multilayer by Optical Waveguide Light-Mode Spectroscopy (OWLS) and AFM. The secondary structure of bovine serum albumin (BSA) adsorbed onto PAH/PSS multilayers was also investigated by Schaaf and coworkers ${ }^{4}$ and it was observed that $\mathrm{PAH}$ as terminal layer has practically no effect on aggregation of BSA. In our earlier paper ${ }^{5}$ we investigated the adsorption of BSA on previously formed poly(allylamine hydrochloride)/poly(sodium 4styrenesulphonate) (PAH/PSS) multilayer with PAH being a terminal layer by stagnation point optical reflectometry. ${ }^{6,7}$ In that study ${ }^{5}$ we showed that in all investigated systems the adsorption of BSA depends on conditions under which the multilayer was formed (ionic strength, $\mathrm{pH}$ and the presence of an anchoring layer), as well as on BSA concentration.

In addition to the mentioned ones, various other experimental methods presented e.g. in review papers ${ }^{8,9}$ have been used to get a better insight into the multilayer formation process, as well as to help in understanding the details of the protein adsorption process on already formed multilayer. For example, electrokinetic measurements have often been used, ${ }^{10-12}$ but in most cases just for the confirmation of the charge reversal during the multilayer formation process at a certain $\mathrm{pH}$. One exception is the study by Köstler ${ }^{12}$ and coworkers who investigated the build-up of PDADMAC/PSS multilayer on a polymer surface following the changes of the zeta potential $v s \mathrm{pH}$ curves. On the other hand, the adsorption of polyelectrolytes on metal oxides (which can be

\footnotetext{
$\dagger$ This article belongs to the Special Issue Chemistry of Living Systems devoted to the intersection of chemistry with life.

* Author to whom correspondence should be addressed. (E-mail: davor.kovacevic@chem.pmf.hr)
} 
compared to the adsorption of one polyelectrolyte layer) is commonly studied and the experimental results very often include zeta potential measurements. ${ }^{13-17}$

The aim of presented study is, therefore, to examine the formation of a polyelectrolyte multilayer on silica particles and the adsorption of a protein on already formed multilayer by means of electrokinetic and spectrophotometric measurements as the function of $\mathrm{pH}$, as well as to compare the obtained results with previously obtained ones on flat surfaces. Polyelectrolyte multilayers were formed by the alternate adsorption of a weakly charged polyelectrolyte poly(allylamine hydrochloride) and a strongly charged polyelectrolyte poly(sodium 4-styrenesulfonate) on which the protein bovine serum albumin (BSA) was additionally adsorbed. The effect of ionic strength and effect of BSA concentration were investigated.

\section{EXPERIMENTAL}

\section{Materials}

For the polyelectrolyte multilayer formation silica particles, $\mathrm{SiO}_{2}$ (Aerosil 200, Degussa, with specific surface area being $200 \mathrm{~m}^{2} \mathrm{~g}^{-1}$ ), polycation poly(allylamine hydrochloride), PAH, $\left(M_{\mathrm{w}}=70000 \mathrm{~g} \mathrm{~mol}^{-1}\right.$, Aldrich), polyanion poly(sodium 4-styrenesulphonate), PSS, $\left(M_{\mathrm{w}}\right.$ $=70000 \mathrm{~g} \mathrm{~mol}^{-1}$, Aldrich) and protein bovine serum albumin, BSA, $\left(M_{\mathrm{w}}=67000 \mathrm{~g} \mathrm{~mol}^{-1}\right.$, Fluka, BioChemika) were used. The supporting electrolyte was potassium chloride (Fluka, Chemika) and $\mathrm{pH}$ was adjusted by adding $\mathrm{HCl}$ and $\mathrm{KOH}$ solution.

\section{Multilayer Formation Methods}

The desired multilayers were formed by the consecutive adsorption of PAH and PSS, with PAH being a terminal layer. Additionally, bovine serum albumin (BSA) was adsorbed on previously formed multilayer. In all adsorption experiments the adsorption time was 30 minutes. The multilayer formation process was performed as follows: The suspension of silica particles was prepared by dispersing them in deionized water $\left(\gamma=3 \mathrm{~g} \mathrm{dm}^{-3}\right)$ and stirred by a magnetic stirrer. After $\mathrm{pH}$ adjustment $10 \mathrm{~mL}$ of silica suspension were transferred into a cuvette. The procedure was repeated for 15 different $\mathrm{pH}$ values. Suspensions were then centrifuged for $30 \mathrm{mi}-$ nutes at $3000 \mathrm{rpm}$. Supernatant was removed and silica particles were reused as a substrate for the adsorption of PAH as the first adsorbed layer.

PAH solution was prepared by dissolving $\mathrm{PAH}$ in deionized water and its concentration was $\gamma=50 \mathrm{mg}$ $\mathrm{dm}^{-3}$. The process of preparing 15 suspensions with different $\mathrm{pH}$ values was the same as for the silica particles and the zeta potential was determined accordingly. After the addition of polyelectrolyte solutions suspen- sions were mixed for 30 minutes. Directly after mixing the zeta potential of the suspensions was measured. For each sample zeta potential measurements were repeated 10 times. After measuring zeta potential suspensions were centrifuged again and as the second layer, PSS was adsorbed on $\mathrm{SiO}_{2} / \mathrm{PAH}$ system. The procedure of the adsorption of PSS $\left(\gamma=50 \mathrm{mg} \mathrm{dm}^{-3}\right)$ and of the second layer of PAH was the same as for the first layer of PAH. Subsequently the protein was adsorbed as a final layer. After the adsorption of the second layer of PAH the suspension was not centrifuged as earlier, but each suspension at a certain $\mathrm{pH}$ value was divided into 3 parts. Each part was centrifuged separately in a cuvette. After the centrifugation and removal of a supernatant in each cuvette $3.33 \mathrm{~mL}$ of the solution of BSA of appropriate $\mathrm{pH}$ value was added. Suspensions were mixed for 30 minutes and the zeta potential of each sample was measured again.

\section{Electrokinetic Measurements}

The electrokinetic (zeta) potential of silica particles and of multilayers was measured by means of a ZetaPlus Zeta Potential Analyser, Brookhaven Instruments Corporation. The instrument uses electrophoretic light scattering and the Laser Doppler Velocimetry method for determination of particle velocity and, from this, the zeta potential. The zeta potential was calculated from mobility values using the Smoluchowski equation. The experiments were performed at three different ionic strength values $\left(I_{c}=5 \mathrm{mmol} \mathrm{dm}{ }^{-3}, I_{c}=10 \mathrm{mmol} \mathrm{dm}^{-3}\right.$ and $I_{c}=20 \mathrm{mmol} \mathrm{dm}^{-3}$ ) as a function of $\mathrm{pH}$.

\section{Adsorption Measurements}

In order to determine the adsorbed amount, the concentration of PSS or BSA in the supernatant solution was determined spectrophotometrically (UV-Vis-NIR spectrophotometer Cary 05E, Varian, USA). In the case of PSS the absorbance was measured at $225 \mathrm{~nm}$ and, in the case of BSA, at $278 \mathrm{~nm}$. Calibration curves were obtained by plotting the measured absorbance $v s$. the concentration of corresponding PSS or BSA samples. PAH does not have chromomeric groups so it is not spectrophotometrically active in UV-Vis region.

\section{RESULTS AND DISCUSSION}

\section{Formation of PAH/PSS/PAH Multilayer on Silica Particles}

Since the electrokinetic measurements represent another alternative method for examining in situ the formation of polyelectrolyte-protein multilayers on solid substrates, we used that method for investigating the properties of the $\mathrm{SiO}_{2} / \mathrm{PAH} / \mathrm{PSS} / \mathrm{PAH}$ system. As the con- 


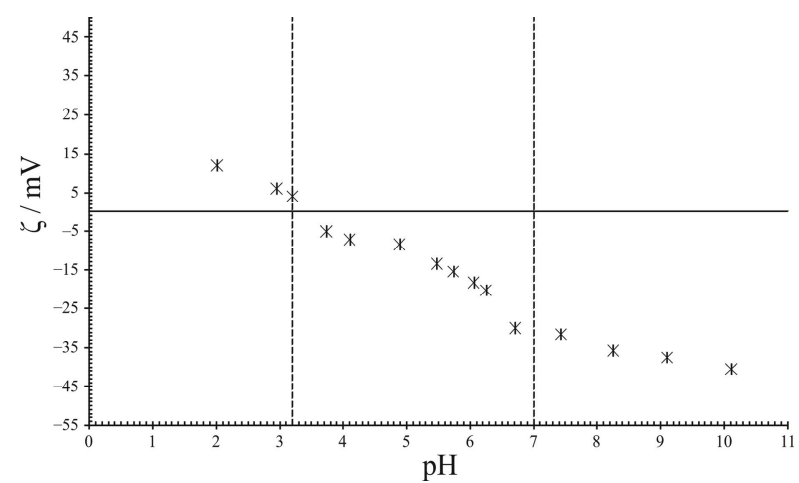

Figure 1. Electrokinetic potential of $\mathrm{SiO}_{2}$ particles in the presence of $\mathrm{KCl}$ as a function of $\mathrm{pH}$ at $25{ }^{\circ} \mathrm{C}$; Experimental parameters: $\gamma\left(\mathrm{SiO}_{2}\right)=3 \mathrm{~g} \mathrm{dm}^{-3}, I_{c}=20 \mathrm{mmol} \mathrm{dm}^{-3}$.

sequence of the fact that $\mathrm{pH}$ (especially in the case of weakly charged polyelectrolytes) plays an important role in the process of formation of polyelectrolyte and polyelectrolyte/protein multilayers the experiments in the $\mathrm{pH}$ range $2<\mathrm{pH}<11$ were performed. Therefore we started our study with the experimental determination of the electrokinetic (zeta) potential of silica particles at $25^{\circ} \mathrm{C}$.

As it is shown in Figure 1 zeta potential of pure silica particles greatly depends on $\mathrm{pH}$ of solution in which particles are dispersed. By increasing the $\mathrm{pH}$ of the solution zeta potential of silica particles starts decreasing reaching the isoelectric point at $\mathrm{pH}_{\text {iep }}=3.2$. Further increase of $\mathrm{pH}$ leads to more negative zeta potential of silica particles.

In the second step the weakly charged polycation poly(allylamine hydrochloride) ${ }^{17}$ was adsorbed as the first layer of the forthcoming multilayer on silica particles. Again, the zeta potential of the formed $\mathrm{SiO}_{2} / \mathrm{PAH}$ particles was measured by means of the electrophoretic light scattering instrument and the results are shown in Figure 2.

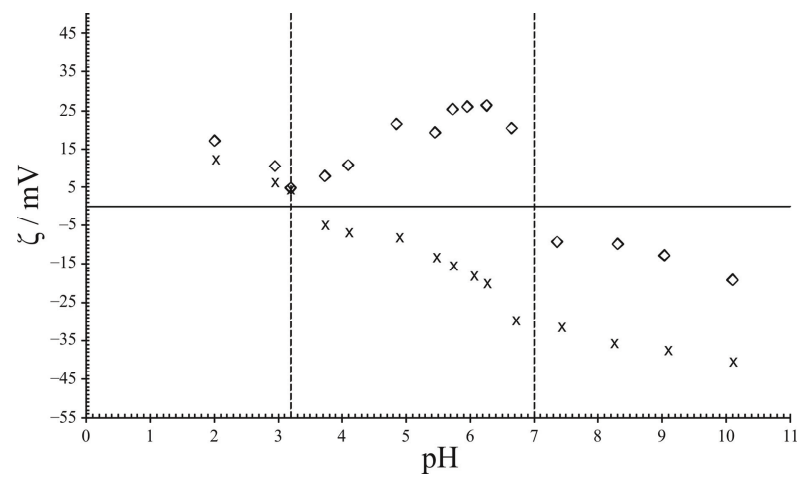

Figure 2. Electrokinetic potential of $\mathrm{SiO}_{2}$ particles before (x) and after $(\diamond)$ the adsorption of $\mathrm{PAH}$ in the presence of $\mathrm{KCl}$ as a function of $\mathrm{pH}$ at $25^{\circ} \mathrm{C}$. Experimental parameters: $\gamma\left(\mathrm{SiO}_{2}\right)=$ $3 \mathrm{~g} \mathrm{dm}^{-3}, \gamma(\mathrm{PAH})=50 \mathrm{mg} \mathrm{dm}^{-3}, I_{c}=20 \mathrm{mmol} \mathrm{dm}^{-3}$.

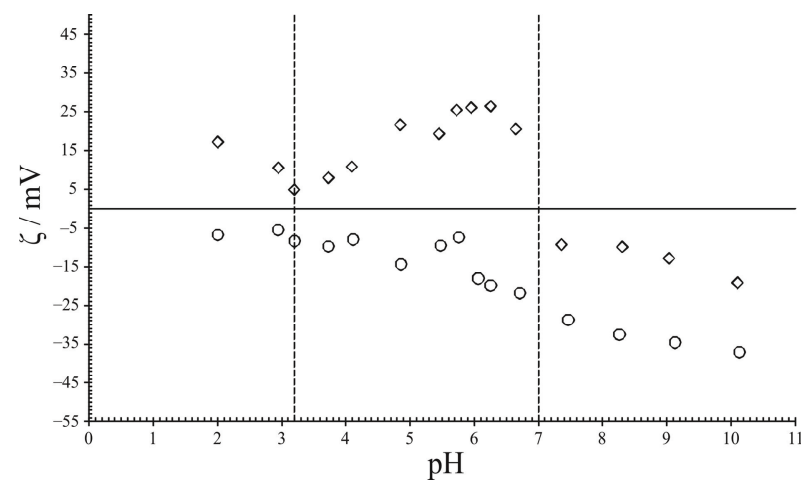

Figure 3. Electrokinetic potential of the $\mathrm{SiO}_{2} / \mathrm{PAH}$ system before $(\diamond)$ and after $(\circ)$ addition of PSS in the presence of $\mathrm{KCl}$ as a function of $\mathrm{pH}$ at $25{ }^{\circ} \mathrm{C}$. Experimental parameters: $\gamma\left(\mathrm{SiO}_{2}\right)=3 \mathrm{~g} \mathrm{dm}^{-3}, \gamma(\mathrm{PSS})=50 \mathrm{mg} \mathrm{dm}^{-3}, I_{c}=20 \mathrm{mmol} \mathrm{dm}^{-3}$.

Since the isoelectric point of $\mathrm{SiO}_{2}$ is determined to be at $\mathrm{pH}_{\text {iep }}=3.2$ (Figure 1) below that value almost no change in the zeta potential was observed due to the pronounced electrostatic repulsion between the positively charged silica surface and positively charged PAH molecules. In that $\mathrm{pH}$ region the positive zeta potential of silica particles remained positive after addition of $\mathrm{PAH}$. In the $\mathrm{pH}$ range 3.2 $<\mathrm{pH}<7$ the positively charged polycation was adsorbed on negatively charged silica particles and the obtained $\mathrm{SiO}_{2} / \mathrm{PAH}$ particles were positively charged. In that $\mathrm{pH}$ region the charge sign of silica particles was reversed from the negative to the positive after addition of PAH. The third type of behavior was observed in the $\mathrm{pH}$ range $\mathrm{pH}>$ 7. Since weak polyelectrolytes as PAH are ionic polymers with the charge densities that can be tuned by simple $\mathrm{pH}$ adjustments, it is clear that the $\mathrm{pH}$ value of the added polyelectrolyte solution plays a very important role in the multilayer formation process. ${ }^{18-20}$ From the potentiometric titrations $^{21,22}$ it was concluded that in the case of the PAH solution the $\mathrm{p} K$ value is about 9 (depending on local environment) which means that PAH chains start to lose protons above $\mathrm{pH} \approx 7$. Following that in the $\mathrm{pH}$ region $\mathrm{pH}>7$ PAH molecules are partially deprotonated and their charge is not sufficient to fully overcharge the negatively charged $\mathrm{SiO}_{2}$ particles. As the consequence, the adsorption of not completely charged $\mathrm{PAH}$ in the $\mathrm{pH}$ range $\mathrm{pH}>7$ leads only to less negative and not to positive values of the zeta potential and the overall charge remains negative.

As expected, in the previous step during PAH adsorption process in the $\mathrm{pH}$ range $\mathrm{pH}<3.2$ due to electrostatic repulsion between positively charged polymer and surface no charge reversal was obtained. In the next step, shown in Figure 3, the negatively charged strong polyanion poly(sodium 4-styrenesulphonate) was adsorbed on previously formed $\mathrm{SiO}_{2} / \mathrm{PAH}$ particles. As it is well known, poly(sodium 4-styrenesulphonate) is a strongly charged polyelectrolyte and its charge does not significantly depend on the $\mathrm{pH}$ of the system. ${ }^{23}$ Hence, 


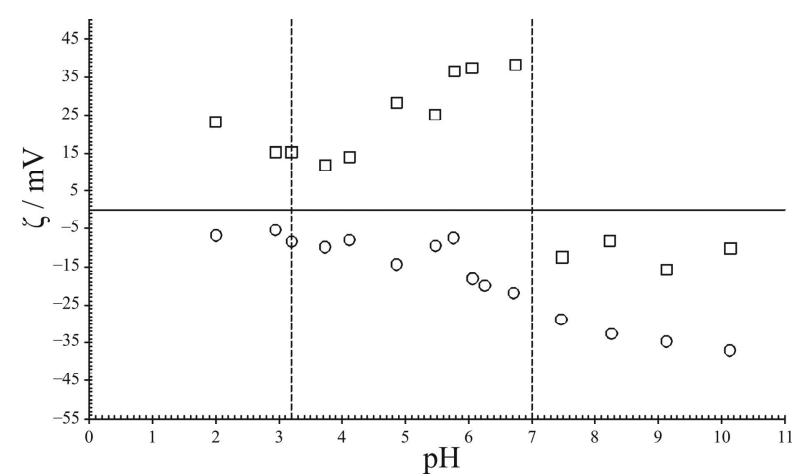

Figure 4. Electrokinetic potential of the $\mathrm{SiO}_{2} / \mathrm{PAH} / \mathrm{PSS}$ system before ( $\odot$ ) and after ( $\square$ ) addition of PAH in the presence of $\mathrm{KCl}$ as a function of $\mathrm{pH}$ at $25{ }^{\circ} \mathrm{C}$. Experimental parameters: $\gamma\left(\mathrm{SiO}_{2}\right)=3 \mathrm{~g} \mathrm{dm}^{-3}, \gamma(\mathrm{PAH})=50 \mathrm{mg} \mathrm{dm}^{-3}, I_{c}=$ $20 \mathrm{mmol} \mathrm{dm}^{-3}$.

above $\mathrm{pH}=3.2$ PSS was adsorbed on silica particles covered with PAH regardless to the $\mathrm{pH}$. Accordingly, the overall charge of the system $\mathrm{SiO}_{2} / \mathrm{PAH} / \mathrm{PSS}$ after the adsorption of poly(sodium 4-styrenesulphonate) was negative in the entire examined $\mathrm{pH}$ region (Figure 3).

On the top of the $\mathrm{SiO}_{2} / \mathrm{PAH} / \mathrm{PSS}$ particles the polycation poly(allylamine hydrochloride) was again adsorbed and the results of zeta potential measurements are presented in Figure 4. Since PAH is, as stated above and contrary to PSS, a weakly charged polyelectrolyte and its charge is $\mathrm{pH}$ sensitive, in the region $\mathrm{pH}>7$ no charge reversal (negative to positive) was observed due to the fact that electrostatic interactions between the negatively charged surfaces and poly(allylamine hydrochloride) are not sufficiently strong. Of course, in the $\mathrm{pH}$ region $\mathrm{pH}<7$ positively charged $\mathrm{PAH}$ molecules are sufficiently charged to change the sign of the zeta potential from the negative to the positive.

\section{Adsorption of BSA on Previously Formed $\mathrm{SiO}_{2} / \mathrm{PAH} / \mathrm{PSS} / \mathrm{PAH}$ Multilayer}

In the final step, the protein bovine serum albumin was adsorbed on previously formed polyelectrolyte multilayer (Figure 5). Taking into account the zeta potential results presented in Figures 1-4 it should be stated here that it seems that two different types of multilayers are formed. At $\mathrm{pH}<3.2$ it is the $\mathrm{SiO}_{2} / \mathrm{PSS} / \mathrm{PAH}$ multilayer and at $\mathrm{pH}$ $>3.2 \mathrm{SiO}_{2} / \mathrm{PAH} / \mathrm{PSS} / \mathrm{PAH}$ multilayer. However, in the forthcoming discussion we are not going to distinguish between these two and we are going to refer to both of them as to polyelectrolyte multilayers. Again, as in the preceding steps, the protein adsorption and the final layer charge depend on the charge of the previously formed multilayer and on the $\mathrm{pH}$ dependence of on the charge of the protein itself. Since the isoelectric point of bovine serum albumin was found to be at 4.7 , above that the $\mathrm{pH}$ value BSA is negatively charged. On the other hand, it

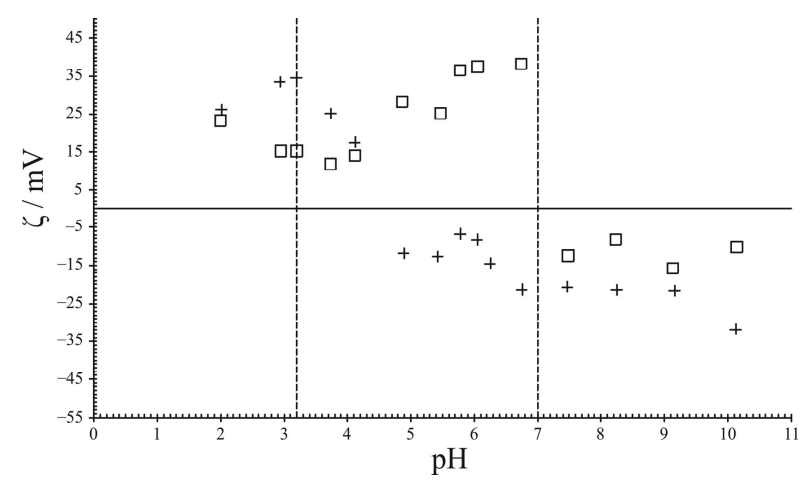

Figure 5. Electrokinetic potential of the $\mathrm{SiO}_{2} / \mathrm{PAH} / \mathrm{PSS} / \mathrm{PAH}$ system before ( $\square$ ) and after $(+)$ addition of BSA in the presence of $\mathrm{KCl}$ as a function of $\mathrm{pH}$ at $25^{\circ} \mathrm{C}$. Experimental parameters: $\gamma\left(\mathrm{SiO}_{2}\right)=3 \mathrm{~g} \mathrm{dm}^{-3}, \gamma(\mathrm{BSA})=1.0 \mathrm{~g} \mathrm{dm}^{-3}, I_{c}=20$ $\mathrm{mmol} \mathrm{dm}{ }^{-3}$.

could be concluded from the results presented in Figure 4 that system $\mathrm{SiO}_{2} / \mathrm{PAH} / \mathrm{PSS} / \mathrm{PAH}$ is negatively charged above $\mathrm{pH}=7$. These observations lead to the conclusion that above $\mathrm{pH}=7$ no BSA adsorption should occur and it was confirmed by our results (Figure 5 ).

\section{Effect of Ionic Strength}

It is well known that the change in ionic strength affects the mobility of the particles, as well as the conformation of polyelectrolytes and proteins in the solution. Therefore, we decided to investigate how ionic strength (i.e. supporting electrolyte concentration) influences the electrokinetic (zeta) potential of $\mathrm{SiO}_{2}$ particles after the adsorption of $\mathrm{PAH}$ in broad $\mathrm{pH}$ range and, later on, if the similar type of effect could be observed when the protein of different concentration is adsorbed on the previously formed multilayer.

In Figure 6 the results of zeta potential measurements for the system $\mathrm{SiO}_{2} / \mathrm{PAH}$ at three different ionic

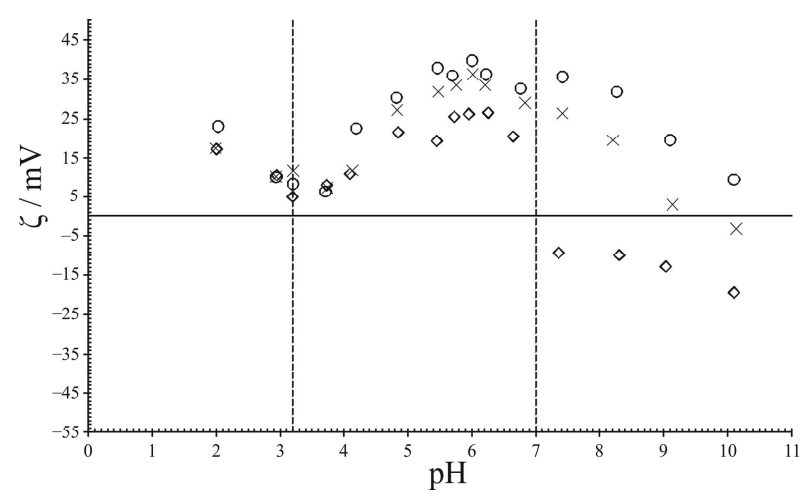

Figure 6. Electrokinetic potential of $\mathrm{SiO}_{2}$ particles after the adsorption of $\mathrm{PAH}$ as a function of $\mathrm{pH}$ at $25^{\circ} \mathrm{C}$ at three different supporting electrolyte $(\mathrm{KCl})$ concentrations. Experimental parameters: $\gamma\left(\mathrm{SiO}_{2}\right)=3 \mathrm{~g} \mathrm{dm}^{-3}, \gamma(\mathrm{PAH})=50 \mathrm{mg} \mathrm{dm}^{-3}, I_{\mathrm{c}}=5$

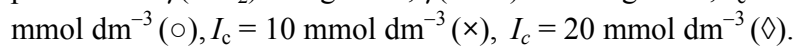




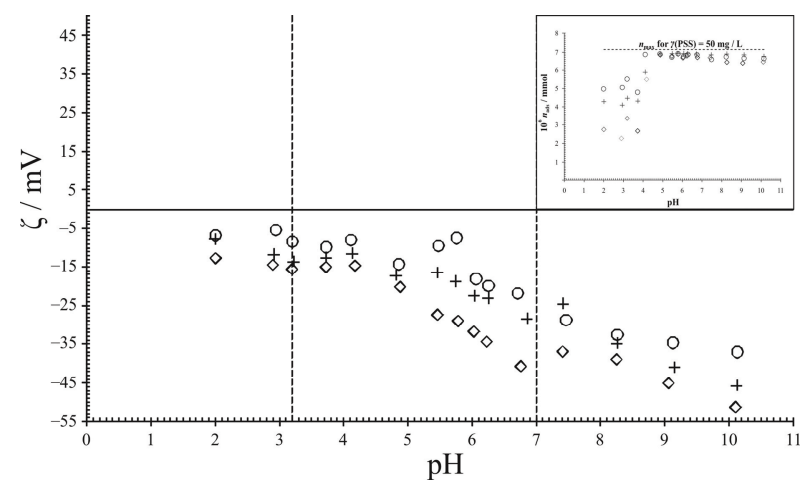

Figure 7. Electrokinetic potential of $\mathrm{SiO}_{2} / \mathrm{PAH}$ system after addition of PSS as a function of $\mathrm{pH}$ at $25{ }^{\circ} \mathrm{C}$ at three different supporting electrolyte $(\mathrm{KCl})$ concentrations. Experimental parameters: $\gamma\left(\mathrm{SiO}_{2}\right)=3 \mathrm{~g} \mathrm{dm}^{-3}, \gamma(\mathrm{PSS})=50 \mathrm{mg} \mathrm{dm}^{-3}, I_{c}=5$ $\mathrm{mmol} \mathrm{dm}{ }^{-3}(\diamond), I_{c}=10 \mathrm{mmol} \mathrm{dm}{ }^{-3}(+), I_{c}=20 \mathrm{mmol} \mathrm{dm}^{-3}(\circ)$. The inset in Figure 7: The adsorbed amount of PSS on $\mathrm{SiO}_{2} / \mathrm{PAH}$ bilayer at three different supporting electrolyte $(\mathrm{KCl})$ concentrations as a function of $\mathrm{pH}$ at $25^{\circ} \mathrm{C}$. Experimental parameters: $\gamma(\mathrm{PSS})=50 \mathrm{mg} \mathrm{dm}^{-3}, I_{c}=5 \mathrm{mmol} \mathrm{dm}^{-3}(+), I_{c}$ $=10 \mathrm{mmol} \mathrm{dm}^{-3}(\circ), I_{c}=20 \mathrm{mmol} \mathrm{dm}^{-3}(\diamond)$.

strength values $\left(I_{c}=5 \mathrm{mmol} \mathrm{dm}{ }^{-3}, I_{c}=10 \mathrm{mmol} \mathrm{dm}^{-3}\right.$ and $I_{c}=20 \mathrm{mmol} \mathrm{dm}^{-3}$ ) are presented as the function of $\mathrm{pH}$. Again, three specific $\mathrm{pH}$ regions could be determined. In the $\mathrm{pH}$ regions $\mathrm{pH}<3.2$ and $3.2<\mathrm{pH}<7$ it is difficult (at least for the investigated ionic strength values) to unambiguously determine the electrolyte concentration effect, although it seems that the zeta potential is increasing with a decreasing ionic strength. On the contrary, the shift of the zeta potential in the $\mathrm{pH}$ region $\mathrm{pH}>7$ after the adsorption of $\mathrm{PAH}$ was clearly the highest for $I_{c}=5 \mathrm{mmol} \mathrm{dm}{ }^{-3}$ and decreased with the increasing salt concentration.

These results could be the consequence of the interplay caused by several factors influenced by changes in $\mathrm{pH}$ and ionic strength, such as the conformational changes of PAH chains, differences in the degree of dissociation of PAH and the number of available surface groups.

Another conclusion that could be drawn from the results shown in Figure 6 is that the increase in ionic strength leads to a shift of the isoelectric point of the $\mathrm{SiO}_{2} / \mathrm{PAH}$ system. It is known from literature ${ }^{24}$ that generally the adsorption of negatively charged species shifts the isoelectric point to the lower and the adsorption of positively charged species to higher $\mathrm{pH}$ values. That is also valid for adsorption of polyelectrolytes, as shown e.g. by Schwarz et al. ${ }^{25}$ for PDADMAC and PEI adsorption on silica and by Shin and coworkers ${ }^{26}$ for PDADMAC adsorption on alumina, being confirmed by the results obtained in this study. Additionally, it is shown that the observed shift of the isoelectric point depends on the ionic strength. At the highest

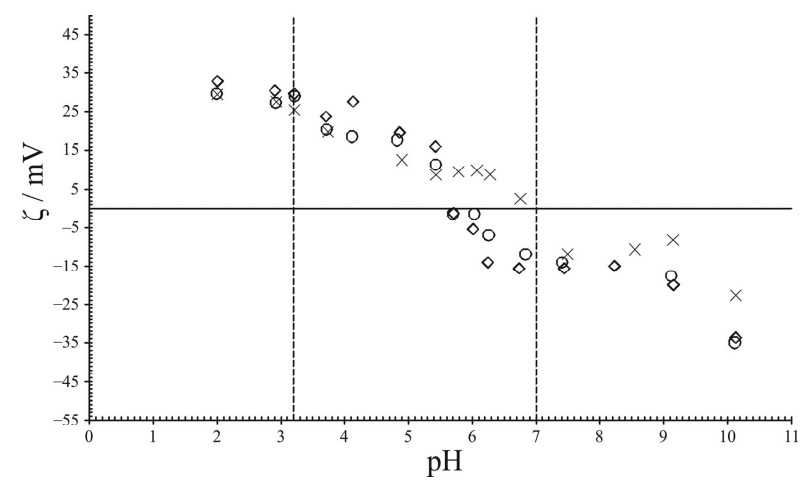

Figure 8. Electrokinetic potential of $\mathrm{SiO}_{2} / \mathrm{PAH} / \mathrm{PSS} / \mathrm{PAH}$ after the adsorption of BSA as a function of $\mathrm{pH}$ at $25^{\circ} \mathrm{C}$ at three different supporting electrolyte $(\mathrm{KCl})$ concentrations.. Experimental parameters: $\gamma\left(\mathrm{SiO}_{2}\right)=3 \mathrm{~g} \mathrm{dm}^{-3}, \gamma(\mathrm{PAH})=50 \mathrm{mg}$ $\mathrm{dm}^{-3}, \gamma(\mathrm{PSS})=50 \mathrm{mg} \mathrm{dm}^{-3}, \gamma(\mathrm{BSA})=0.1 \mathrm{~g} \mathrm{dm}^{-3}, I_{c}=5 \mathrm{mmol}$ $\mathrm{dm}^{-3}(\diamond), I_{\mathrm{c}}=10 \mathrm{mmol} \mathrm{dm}^{-3}(\circ), I_{c}=20 \mathrm{mmol} \mathrm{dm}^{-3}(\times)$.

ionic strength used $\left(20 \mathrm{mmol} \mathrm{\textrm {dm } ^ { - 3 }}\right)$ the isoelectric point of the $\mathrm{SiO}_{2} / \mathrm{PAH}$ system is found to be at $\mathrm{pH}_{\text {iep }} \approx$ 7.2. The shift of the isoelectric point is more pronounced for lower salt concentrations leading to the value of $\mathrm{pH}_{\text {iep }}=9.0$ for $I_{c}=10 \mathrm{mmol} \mathrm{dm}{ }^{-3}$, while for the lowest ionic strength used $\left(5 \mathrm{mmol} \mathrm{dm} \mathrm{m}^{-3}\right)$ isoelectric point could not even be detected in the investigated $\mathrm{pH}$ range.

The comparison of the zeta potential values obtained for different ionic strengths after the adsorption of poly(sodium 4-styrenesulphonate) is shown in Figure 7. As expected, all obtained zeta potential values were negative.

As stated earlier PSS charge does not depend on the $\mathrm{pH}$ of the solution, and its structure is more rigid than the PAH structure. Therefore, the influence of ionic strength on the adsorption of PSS is less pronounced than the influence observed in the case of PAH. However, there is a certain trend of the decrease in the zeta potential with the increase in ionic strength. In order to test the results from Figure 7 and the corresponding conclusions the non adsorbed amount of PSS (i.e. PSS concentration in the supernatant) was determined for all three investigated ionic strength values spectrophotometrically. Results of these measurements are shown in the inset in Figure 7. In the $\mathrm{pH}$ range $\mathrm{pH}>4$ the maximum adsorption was reached which is consistent with the results shown in Figure 7 . The dependence of the zeta potentials for $\mathrm{SiO}_{2} / \mathrm{PAH} / \mathrm{PSS} / \mathrm{PAH}$ system on ionic strength was also examined (not shown here) and the results are similar to those obtained for $\mathrm{SiO}_{2} / \mathrm{PAH}$ system.

Finally, the effect of ionic strength on the zeta potential after the adsorption of bovine serum albumin on previously formed multilayer was examined. Results shown in Figure 8 could lead to the conclusion that no 


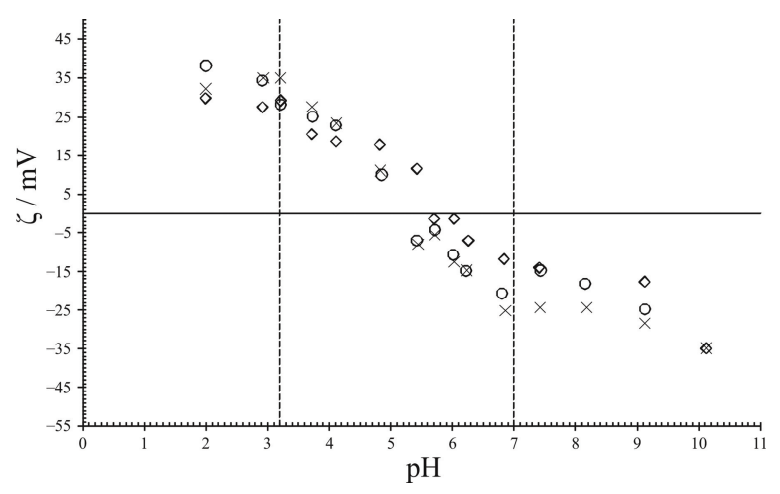

Figure 9. Electrokinetic potential of $\mathrm{SiO}_{2} / \mathrm{PAH} / \mathrm{PSS} / \mathrm{PAH}$ system after the adsorption of BSA as a function of $\mathrm{pH}$ at 25 ${ }^{\circ} \mathrm{C}$ for the different BSA concentrations. Experimental parameters: $\gamma\left(\mathrm{SiO}_{2}\right)=3 \mathrm{~g} \mathrm{dm}^{-3}, \gamma(\mathrm{PAH})=50 \mathrm{mg} \mathrm{dm}^{-3}, \gamma(\mathrm{PSS})=$ $50 \mathrm{mg} \mathrm{dm}^{-3}, \gamma($ BSA $)=0.1 \mathrm{~g} \mathrm{dm}^{-3}(\diamond), \gamma($ BSA $)=0.5 \mathrm{~g} \mathrm{dm}^{-3}$ $(\circ), \gamma($ BSA $)=1.0 \mathrm{~g} \mathrm{dm}^{-3}(\times), I_{c}=10 \mathrm{mmol} \mathrm{dm}^{-3}$.

significant difference in the zeta potential after the adsorption of BSA $\left(\gamma(\mathrm{BSA})=0.1 \mathrm{~g} \mathrm{dm}^{-3}\right)$ at various ionic strengths is observed.

Similar results were obtained in the case of BSA adsorption at concentrations of $0.5 \mathrm{~g} \mathrm{dm}^{-3}$ and $1.0 \mathrm{~g}$ $\mathrm{dm}^{-3}$. It seems that the influence of ionic strength on the protein adsorption (at least at the investigated supporting electrolyte concentrations) is not as pronounced as in the case of the polyelectrolyte adsorption. One of the reasons could be the more compact protein structure compared to the polye-lectrolyte structure.

\section{Effect of BSA Concentration}

One of the main aims of this study was to determine the effect of BSA concentration on the zeta potential of the formed multilayer particles. In our previous paper ${ }^{5}$ we observed (by means of stagnation point optical reflectometry) that when the mass concentration of BSA was $\gamma \geq 0.75 \mathrm{~g} \mathrm{dm}^{-3}$ the adsorbed amount of BSA started to decrease meaning that a desorption process started. It seems that BSA molecules were present in excess of the available multilayer area and after some time weakly bound molecules left the surface. Since the mentioned results were obtained on the flat surface, it was tempting to compare them with the results obtained on particles. In Figure 9 zeta potentials of the system after BSA adsorption for various BSA concentrations at $I_{c}=10 \mathrm{mmol}$ $\mathrm{dm}^{-3}$ are shown.

Here the most interesting $\mathrm{pH}$ region is $4.7<\mathrm{pH}<$ 8 , since in that $\mathrm{pH}$ range BSA is negatively $\left(\mathrm{pH}_{\text {iep }}=4.7\right)$ and the multilayer $\mathrm{SiO}_{2} / \mathrm{PAH} / \mathrm{PSS} / \mathrm{PAH}$ is positively charged. If the adsorbed amount of BSA would increase with the increase in protein concentration, it would mean that the change in the zeta potential (relative to the $\mathrm{SiO}_{2} / \mathrm{PAH} / \mathrm{PSS} / \mathrm{PAH}$ system) should also increase. In Figure $\left.9\left(I_{c}=10 \mathrm{mmol} \mathrm{dm}\right)^{-3}\right)$ that increase is not very

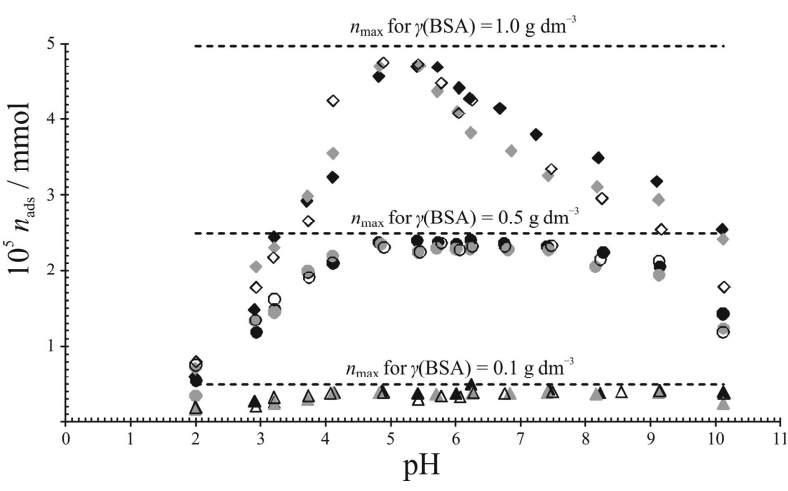

Figure 10. The adsorbed amount of BSA at three different BSA concentrations and at three different ionic strengths as a function of $\mathrm{pH}$ at $25^{\circ} \mathrm{C}$. Experimental parameters: $\gamma(\mathrm{BSA})=$ $0.1 \mathrm{~g} \mathrm{dm}^{-3}$ (triangle), $\gamma(\mathrm{BSA})=0.5 \mathrm{~g} \mathrm{dm}^{-3}$ (circle), $\gamma(\mathrm{BSA})=$ $1.0 \mathrm{~g} \mathrm{dm}^{-3}$ (diamond); $I_{c}=5 \mathrm{mmol} \mathrm{dm}^{-3}$ (black), $I_{c}=10 \mathrm{mmol}$ $\mathrm{dm}^{-3}$ (grey), $I_{c}=20 \mathrm{mmol} \mathrm{dm}^{-3}$ (empty).

noticeable and from these results it is not easy to deduce about the effect of BSA concentration on the adsorption process, but it seems that it is not as pronounced as in the case of adsorption on flat surfaces. Similar results were obtained for the adsorption of BSA at two other investigated ionic strengths of $I_{c}=5 \mathrm{mmol} \mathrm{dm}^{-3}$ and $I_{c}=$ $20 \mathrm{mmol} \mathrm{dm}^{-3}$ (not shown here).

In order to confirm the above mentioned results, the adsorbed amount of BSA on previously formed multilayer was determined spectrophotometrically. Results of adsorbed amounts of BSA at three different protein concentrations and at three different ionic strengths are shown in Figure 10.

As expected, the maximal adsorption amount was detected in the $\mathrm{pH}$ region $4.7<\mathrm{pH}<8$ where the interplay between multilayer and BSA charges leads to the most pronounced adsorption. These results are in accordance with the zeta potential results obtained in this study, but also with other adsorption results from the literature. For example, Martins and coworkers ${ }^{27}$ showed by using QCM-D that the behavior of HSA on chitosan/alginate multilayered systems can be tuned by adjusting $\mathrm{pH}$, as well as other parameters such as layer number and polyelectrolate terminal layer. The importance of the control of the internal ionization of weak polyelectrolyte multilayers was also stressed by Tristan et al. ${ }^{28}$ who showed that tunable glucose oxidase (GOX) adsorption on PAH/PAA multilyer was possible by simply changing the buildup $\mathrm{pH}$ conditions which might open a route toward simple tuning of protein adsorption.

\section{CONCLUSION}

Electrokinetic measurements were applied for analyzing the formation of polyelectrolyte multilayers and for 
monitoring the adsorption of BSA on previously formed multilayer. It was shown that the adsorption of PAH as the first layer significantly depends on ionic strength and on the $\mathrm{pH}$ of the solution. During that adsorption process the increase in ionic strength leads to the lower values of the zeta potential. Isoelectric point of the $\mathrm{SiO}_{2} / \mathrm{PAH}$ system is shifted when compared to isoelectric point of pure silica particles. That shift is more pronounced for lower ionic strength values. Since PSS is a strong polyelectrolyte, the influence of $\mathrm{pH}$ and ionic strength on PSS adsorption is less pronounced than in the case of PAH adsorption. The influence of ionic strength on the adsorption of BSA was not as apparent as in the case of PAH and PSS adsorption. Finally, the effect of BSA concentration on the adsorption process was not as significant as in the case of the adsorption on flat surfaces. It could be concluded that, in order to control the process of multilayer formation, several factors need to be taken into account. The ones that noticeably influence the emergence of a new layer are ionic strength, $\mathrm{pH}$ and (in some cases) adsorbing species concentration. Acquired results are useful as supplementary data in the research of formation of polyelectrolyte and polyelectrolyte-protein multilayers on silica particles.

Acknowledgements. This research was supported by the Ministry of Science, Education and Sports of the Republic of Croatia (project No. 119-1191342-2961) and by the COST Action D43.

\section{REFERENCES}

1. G. Decher and J. D. Hong, Macromol. Chem. Macromol. Symp. 46 (1991) 321-327.

2. M. Müller, B. Kessler, and W. Ouyang, Z. Phys. Chem. 221 (2007) 127-138.

3. C. Gergely, S. Bahi, B. Szalontai, H. Flores, P. Schaaf, J. C. Voegel, and F. J. G. Cuisinier, Langmuir 20 (2004) 5575-5582.

4. P. Schwinte, V. Ball, B. Szalontai, Y. Haikel, J. C. Voegel, and P. Schaaf, Biomacromolecules 3 (2002) 1135-1143.
5. E. Primorac, I. Đapić, N. Štrbe, and D. Kovačević, Colloids Surf. B 76 (2010) 305-310.

6. D. Kovačević, S. van der Burgh, A. de Keizer, and M. A. Cohen Stuart, Langmuir 18 (2002) 5607-5612.

7. D. Kovačević, S. van der Burgh, A. de Keizer, and M. A. Cohen Stuart, J. Phys. Chem. B 107 (2003) 7998-8002.

8. R. v. Klitzing, Phys. Chem. Chem. Phys. 8 (2006) 5012-5033.

9. M. Schönhoff, Curr. Opinion Colloid Interface Sci. 8 (2003) 86-95.

10. M. Rusu, D. Kuckling, H. Möhwald, and M. Schönhoff, J. Colloid Interface Sci. 298 (2006) 124-131.

11. J. E. Wong, H. Zastrow, W. Jaeger, and R. von Klitzing, Langmuir 25 (2009) 14061-14070.

12. S. Köstler, V. Ribitsch, K. Stana-Kleinschek, G. Jakopic, and S. Strnad, Colloids Surf. A 270-271 (2005) 107-114.

13. S. Chibowski, E. Grzadka, and J. Patkowski, Colloids Surf. A 326 (2008) 191-203.

14. S. Chibowski, E. Grzadka, and J. Patkowski, Croat. Chem. Acto 82 (2009) 623-631.

15. D. Kovačević, D. Mazur, T. Preočanin, and N. Kallay, Adsorption 16 (2010) 405-412.

16. M. Kolasinska, M. Zembala, M. Krasowska, and P. Warszynski, J. Colloid Interface Sci. 326 (2008) 301-304.

17. B. Jachimska, T. Jasinski, P. Warszynski, and Z. Adamczyk, Colloids Surf. A 355 (2010) 7-15.

18. S. S. Shiratori and M. F. Rubner, Macromolecules 33 (2000) 4213-4219.

19. M. F. Rubner, in: G. Decher, J. Schlenoff (Eds.), Multilayer Thin Films, Wiley-VCH, 2003, pp. 133-154.

20. M. Elzbieciak, M. Kolasinka, and P. Warszynski, Colloids Surf. A 321 (2008) 258-261.

21. M.-K. Park, S. Deng, and R. Advincula, J. Am. Chem. Soc. 126 (2004) 13723-13731.

22. T. Mauser, C. Dejugnat, and G. B. Sukhorukov, Macromol. Rapid Commun. 25 (2004) 1781-1785.

23. Z. Adamczyk, B. Jachimska, T. Jasiński, P. Warszyński, and M. Wasilewska, Colloids Surf. A 343 (2009) 96-103.

24. D. Kovačević, N. Kallay, I. Antol, A. Pohlmeier, H. Lewandovski, and H.-D. Narres, Colloids Surf. A 140 (1998) 261-267.

25. S. Schwarz, K.-J. Eichhorn, E. Wischerhoff, A. Laschewsky, Colloids Surf. A 159 (1999) 491-501.

26. Y-J. Shin, C.-C. Su, Y.-H. Shen, Mater. Res. Bull. 41 (2006) 1964-1971.

27. G. V. Martins, E. G. Merino, J. F. Mano, and N. M. Alves, Macromol. Biosci. 10 (2010) 1444-1455.

28. F. Tristan, G. Palestino, J.-L. Menchaca, E. Perez, H. Atmani, F. Cuisinier, and G. Ladam, Biomacromolecules 10 (2009) 2275-2283. 